\title{
Advisory Group on Greenhouse Gases Established Jointly by WMO, UNEP, and ICSU
}

This Advisory Group has been established to ensure adequate follow-up of the recommendations of the International Conference on the Assessment of the Role of Carbon Dioxide and other Greenhouse Gases in Climate Variations and Associated Impacts, which was held in Villach, Austria, in October 1985. 'Greenhouse Gases' is an informal term that is used for all radiatively active constituents in the atmosphere which collectively tend to increase the temperature of the lower atmosphere after the manner of a greenhouse or glasshouse.

The Advisory Group on Greenhouse Gases (AGGG), which met at the WMO Headquarters in Geneva on 1-2 July 1986 under the chairmanship of Professor F.K. Hare (Canada), strongly supported the statement emanating from the 1985 Villach conference, that the effects of increases in carbon dioxide $\left(\mathrm{CO}_{2}\right)$ and other trace-gases which cause the 'greenhouse effect' (such as methane, chlorofluorocarbons [CFCs], and nitrous oxide) could produce increases in global mean temperature of between $1.5^{\circ}$ and $4.5^{\circ} \mathrm{C}$ by the end of the first half of the next century, when the corresponding rise in sea-level (largely because of the expansion of ocean water) might reach between 20 and 140 centimetres. The results of ongoing research presented since the Villach Conference (such as the dramatic decreases in the ozone layer over the Antarctic* and the asymmetry in the responses of the ocean around Antarctica and of the northern seas around the Arctic) heightens the urgency of the concern expressed in Villach.

The AGGG will carry out two main tasks: (1) biennial reviews of international and regional studies related to greenhouse gases, and (2) aperiodic assessments of the rates of increases in the concentrations of greenhouse gases and of the effects of such increases. The Advisory Group was particularly conscious of the need to develop a mechanism that would provide information on recent developments to a wide audience.

The AGGG stressed the need to improve our basic understanding of the climatic system and its responses to both natural and Man-made forcing mechanisms. As the ozone depletion problem* and the greenhouse gas problem $\dagger$ are interlinked through the impact of the same chemicals, $+\dagger$ the Group urged that the study of these two questions be combined.

In the light of the Villach recommendations for further studies of the socio-economic impacts of climatic change, it was suggested that studies should be carried out in a number of areas such as the monsoon region of S.E. Asia, the
Great Lakes region of North America, Europe, and the circumpolar region in the Arctic.

The AGGG suggested that there are two preventive measures which should be considered to alleviate the problem: (i) energy conservation measures, especially those increasing the efficiency of energy use, and (ii) substitution for CFCs in a number of uses for which alternatives are available.** This latter measure would help because the CFCs have not only become the second most important group of greenhouse gases after $\mathrm{CO}_{2}$, but they also have deleterious effects on the ozone layer. In this connection, consideration should also be given to the need for developing international agreements for the control of the CFCs. $\S$

The members of the AGGG are F.K. Hare (Canada, Chairman), B. Bolin (Sweden), G. Golitsyn (USSR), G.T. Goodman (UK), M. Kassas (Egypt), S. Manabe (USA), and G.F. White (USA). The Chairman of the Villach Conference, J.P. Bruce (Canada), participated in the first meeting of the AGGG.

\author{
Thomas D. PotTer, Director \\ World Climate Programme Department \\ World Meteorological Organization \\ Avenue Giuseppe-Motta 41 \\ 1211 Geneva 20 \\ Switzerland.
}

\begin{abstract}
* See e.g. Ralph Kazarian's “Alarming Depletion of Ozone Layer Above Antarctica: Scientists Seeking Cause', published on page 178 of our Summer issue, and Professor F. Sherwood Rowland's Guest Comment on pp. 193-4 of our Autumn one.-Ed.

$\dagger$ See the short communication entitled 'Expectations and Problems of a Warming World', published on pp. 262-3 of our latest issue. - Ed.

t+ See the note entitled 'Links Between Ozone Depletion and the Greenhouse Effect' on page 364 of this issue. - Ed

** See the 'DuPont Position Statement on the Chlorofluorocarbon-Ozone-Greenhouse Issues' on pp. 363-4 of this issue.-Ed.

$\S$ See the report by Dr Joseph P. Glas (following his 'Dupont Position Statement on the Chlorofluorocarbon-Ozone-Greenhouse Issues' published on our two preceding pages) of the 'First Session of the Ad Hoc Working Group of Legal and Technical Experts for the Preparation of the Protocol on Chlorofluorocarbons to the Vienna Convention for the Protection of the Ozone Layer (Vienna Group)' to be published in the Conferences \& Meetings section of our next issue. - Ed.
\end{abstract}

\section{Scientists Obtain New Midwinter Data on Physical Processes and Life in Ice-covered Antarctic Sea}

An international team of scientists aboard a German research ship has gathered previously unattainable information about physical processes and plant and animal life in an ice-covered sea off Antarctica in midwinter. The scientists said their findings will require 'significant revision' of current ideas of physical and biological processes during the sunless Antarctic winters. Despite extremely low levels of sunlight, biologists reported observing healthy plant and animal life which 'had adapted well to the harsh winter environment in and under the ice-sheet'.

In another unexpected finding, Dr Arnold L. Gordon, an American scientist who had been on the research ship, said that preliminary data suggest there is a much greater flow of heat from the ocean to the atmosphere than had previously been thought. Dr Gordon, a physical oceanographer at the Lamont-Doherty Geological Observatory in Palisades, N.Y, said 'The coupling between the ocean and atmosphere is greater than we thought, and plays a much more significant role in the global climate system'.

Until this expedition, knowledge of winter conditions in the southern oceans had been limited to inferences from summer observations, to data acquired during the 1981 US-USSR investigation of the northern third of the Weddell Sea ice, to observations from a few coastal stations, and to data obtained in 1912 during a cruise of the German ship Deutschland.

The 350-feet ( $c$ a $107 \mathrm{~m}$ )-long West German ship Polarstern, with 50 scientists aboard, left Bahia Blanca, Argen- 